\title{
PENURUNAN NYERI KEPALA PADA LANSIA DENGAN HIPERTENSI MENGGUNAKAN RELAKSASI AUTOGENIK DI KELURAHAN MERSI PURWOKERTO
}

\section{DECREASED HEADACHE ON THE ELDERLY WITH HYPERTENSION USING AUTOGENIC RELAXATION IN MERSI PURWOKERTO}

\author{
Dwi Novitasari ${ }^{*}$, Ikit Netra Wirakhmi \\ ${ }^{* 1}$ Universitas Harapan Bangsa Purwokerto, Jl. Raden Patah No 100, Kembaran, Purwokerto, Email: \\ dwinovitasari@uhb.ac.id, Indonesia \\ ${ }^{2}$ Universitas Harapan Bangsa Purwokerto, Jl. Raden Patah No 100, Kembaran, Purwokerto, Indonesia
}

ABSTRACT

Background: Headache in the occipital region is the most common symptom of hypertension, caused by enhanchement intra-cranial pressure and vasoconstriction resulting in decreased perfusion of cerebral tissue. This causes insomnia, decreased concentration and decreased ability of daily living activity. Autogenic relaxation causes vasodilation and a calm emotional response that increases the response of the parasympathetic system. This modulation stimulus can decrease perception of headache.

Objective: The aims of this study was to find out how the reduction of headache on hypertension before and after autogenic relaxation.

Methods: The design of this research was pre experimental with one group pretest-postest design approach. The sample are 38 patients with hypertension who complained of headache in Mersi Purwokerto. Selection has been using purposive sampling. Measurement of head pain using visual analog scale. Data analysis using Wilcoxon test.

Results: The mean headache before the autogenic relaxation technique was 5.24, and the mean headache after autogenic relaxation technique was 3.47 , including the range of moderate pain. There was a significant difference between headache before and after the autogenic relaxation technique with $p$ value: 0,000 . T.
\end{abstract}

Conclusion: Autogenic relaxation can be used by the elderly with hypertension to reduce headache.

Keywords: autogenic relaxation, headache, hypertension.

\section{PENDAHULUAN}

Jumlah penduduk dari tahun ke tahun semakin meningkat. Hal ini berefek pada peningkatan jumlah lansia. ${ }^{1}$ Degenerasi pada sistem kardiovaskular lansia seperti kekakuan dan penebalan katup jantung, penurunan elastisitas dinding aorta, penurunan fungsi jantung $1 \%$ setiap tahun sehingga menyebabkan penurunan kontraksi dan curah jantung. Hal ini menyebabkan hipertensi. ${ }^{2}$ Hipertensi yang sering diderita lansia yaitu jenis isolated sistolic hypertension yaitu hanya tekanan darah sistolik saja yang mengalami peningkatan. Penurunan Nyeri Kepala pada Lansia dengan Hipertensi Menggunakan Relaksasi Autogenik di Kelurahan Mersi Purwokerto MIK P-ISSN 2252-3413, E-ISSN 2548-6268

Hal tersebut terjadi sebagai bagian proses normal degerenasi yang terjadi pada lansia. ${ }^{3}$

Nyeri kepala merupakan gejala yang paling sering dikeluhkan penderita hipertensi karena peningkatan tekanan intra kranial. $^{2}$ Lokasi nyeri kepala yang paling sering dikeluhkan adalah di area oksipital. Pusing (dizziness) juga sering dikeluhkan, hal ini disebabkan karena vasokonstriksi pembuluh darah sehingga terjadi penurunan perfusi jaringan serebral. Nyeri kepala yang tidak diatasi akan berakibat penurunan kualitas tidur atau insomnia, sehingga berefek juga pada penurunan daya konsentrasi dan 
penurunan kemampuan pemenuhan activity daily living. ${ }^{3}$

Fisiologi nyeri dimulai dengan transduksi yaitu rangsangan substansi $P$ (prostaglandin) di area sel yang mengalami injuri terhadap reseptor nyeri (nosiseptor). Proses selanjutnya adalah transmisi oleh saraf nosiseptik menuju spinal cord. Perjalanan nyeri dilanjutkan oleh saraf asenden menuju ke talamus dan pusat nyeri di korteks serebri. Persepsi nyeri seseorang dapat dimodulasi secara endogenous dengan stimulasi opiat endogenous seperti beta endorpin. Stimulus modulasi mampu menurunkan persepsi nyeri seseorang sehingga nyeri yang dirasakan dapat menurun. ${ }^{4,5}$

Penatalaksanaan nyeri dapat dilakukan cara farmakologi menggunakan obat non opiat analgesik, opiat analgesik, dan obat anestetik. ${ }^{6}$ Penatalaksaan non farmakologis nyeri merupakan intervensi keperawatan mandiri seperti terapi relaksasi autogenik. ${ }^{7}$ Relaksasi autogenik membantu individu untuk dapat mengendalikan beberapa fungsi tubuh seperti tekanan darah, denyut jantung, dan aliran darah. Selama latihan seseorang dipandu untuk rileks dengan situasi yang tenang dan sunyi, ringan dan hangat yang menyebar ke seluruh tubuh. ${ }^{8}$

Arteri perifer mengalami vasodilatasi sehingga menimbulkan rasa hangat yang menjalar. Efek hangat akan menyebabkan darah mengalir secara teratur dan membuat tekanan darah menjadi menurun. Respon emosi dan efek menenangkan yang ditimbulkan oleh relaksasi ini mengubah aktivitas saraf simpatis menjadi dominan sistem saraf parasimpatis. ${ }^{9}$ Sistem saraf parasimpatis akan merespon modulasi nyeri dengan produksi hormon beta endorpin, sehingga nyeri dapat menurun. ${ }^{5}$

Melalui studi pendahuluan dilakukan pada lansia yang tergabung dalam kelompok peduli hipertensi kelurahan Mersi sejumlah 42 lansia. Sebanyak 16 lansia hipertensi mempunyai tekanan darah rata-rata 163,9 $191,4 \mathrm{mmHg}$. Seluruh lansia penderita hipertensi tersebut mengeluhkan nyeri kepala di kepala bagian depan dan tengkuk. Menurut ketua kelompok peduli hipertensi lansia mulai sadar mengontrol tekanan darahnya dengan datang ke Posyandu lansia per bulan, melakukan senam lansia setiap 1 pekan sekali, dan mengikuti edukasi tentang pengendalian hipertensi oleh pembina. Penelitian tentang pengaruh relaksasi autogenik untuk menurunkan tekanan darah pada lansia dengan hipertensi di Kelurahan Mersi Purwokerto menunjukkan hasil penurunan yang signifikan dengan rata-rata tekanan darah sistolik sebesar $8,25 \mathrm{mmHg}$ ( $p$-value $0,002) .^{10}$ Penurunan tekanan darah dapat menurunkan nyeri kepala penderita hipertensi. ${ }^{3}$

Berdasarkan fenomena tersebut, penulis tertarik untuk mengadakan penelitian tentang penurunan nyeri kepala pada lansia dengan 
hipertensi sebelum dan setelah relaksasi autogenik di kelurahan Mersi, Purwokerto Timur. Tujuan penelitian ini untuk mengetahui bagaimanakah penurunan nyeri kepala penderita hipertensi sebelum dan setelah relaksasi autogenik.

\section{BAHAN DAN CARA PENELITIAN}

Penelitian ini menggunakan pre experimental design dengan pendekatan one group pretest-postest design. Populasi penelitian ini adalah lansia penderita hipertensi yang tergabung dalam kelompok peduli hipertensi di Kelurahan Mersi Purwokerto. Sampel penelitian sejumlah 38 orang penderita hipertensi yang mengeluh nyeri kepala. Pemilihan menggunakan purposive sampling. Kriteria sampel penelitian ini yaitu 1) Bersedia menjadi responden penelitian. 2) Melakukan kontrol rutin tekanan darah setiap bulan.

Relaksasi autogenik dilakukan sebanyak 3 kali selama 1 minggu sebelum tidur. Prosedur relaksasi autogenik diawali dengan 1) Memejamkan mata dan bernafas dengan pelan (menarik nafas melalui hidung dan keluarkan melalui mulut), prosedur diulangi 3-5 kali. 2) Sugesti rasa berat dimulai dari tangan dan kaki yang dominan dan bergantian kaki lainnya. Sugesti berat dapat diulang-ulang sekitar 6 kali. 3) Sugesti rasa hangat dimulai dari tangan dan kaki yang dominan dan bergantian tangan Sugesti berat dapat diulang-ulang sekitar 6 kali. 4)
Sugesti rasa hangat dan rileks di area jantung agar berdetak dengan tenang dan teratur. 5) Sugesti rasa rileks pada pernafasan agar tenang dan teratur. 6) Sugesti rasa hangat pada abdomen atau hati. 7) Sugesti rasa dingin pada kepala. Sugesti dingin dimulai dari area dahi dan menyebar ke suluruh kepala. Sugesti diulangi sekitar 6 kali. Setiap sesi relaksasi autogenik membutuhkan waktu total sekitar 15-20 menit.

Pengambilan data penelitian dilakukan bulan April 2018 menggunakan visual analog scale. Uji normalitas data nyeri kepala lansia sebelum dan setelah relaksasi menggunakan uji Shapiro Wilk. Hasil uji tersebut nilai $p$ sebelum: 0,000 dan nilai $p$ sesudah: 0,007 sehingga uji hipotesis menggunakan uji non parametrik Wilcoxon test.

\section{HASIL DAN PEMBAHASAN}

Karakteristik Responden

Tekanan Darah

Tabel 1. Karakteristik reponden: tekanan darah $(\mathrm{mmHg}), \mathrm{n}: \mathbf{3 8}$

\begin{tabular}{lrrrrr}
\hline & Mean & \multicolumn{2}{c}{$\begin{array}{l}\text { Std } \\
\text { dev }\end{array}$} & Min & \multicolumn{1}{l}{ Max } \\
\hline Sistolik & 165,13 & 18,07 & 140 & 220 \\
\hline Diastolik & 91,32 & 12,40 & 70 & 120 \\
\hline Sumber: Data & Primer 2018 & & &
\end{tabular}

Berdasarkan tabel tersebut rata-rata tekanan darah sistolik lansia sebesar 165, 13 $\mathrm{mmHg}$ dan diastolik 91,32 $\mathrm{mmHg}$. Rata-rata tekanan darah lansia tersebut termasuk kategori hipertensi derajat 2. 


\section{Denyut Nadi}

Tabel 2. Karakteristik reponden: denyut jantung (kali / menit), n: $\mathbf{3 8}$

\begin{tabular}{llll}
\hline Mean & Std dev & Min & Max \\
\hline 89,00 & 8,57 & 78 & 110 \\
\hline
\end{tabular}

Sumber: Data Primer 2018

Berdasarkan tabel tersebut diketahui rata-rata denyut jantung lansia sebesar 89, 00 kali / menit dan termasuk rentang normal.

Analisis Univariat

Analisis univariat menggunakan uji deskriptif disajikan dalam tabel berikut ini.

Tabel 3. Skala Nyeri Kepala Sebelum dan Setelah Teknik Relaksasi Autogenik, n: 38

\begin{tabular}{lcccc}
\hline & Mean & $\begin{array}{c}\text { Std. } \\
\text { dev }\end{array}$ & Min & max \\
\hline Sebelum & 5,24 & 0,17 & 4 & 8 \\
\hline Setelah & 3,47 & 0,31 & 0 & 6 \\
\hline
\end{tabular}

Sumber: Data Primer 2018

Berdasarkan tabel tersebut diketahui bahwa rata-rata nyeri kepala sebelum teknik relaksasi autogenik pada lansia sebesar 5,24 , dan rata-rata nyeri kepala setelah teknik relaksasi autogenik pada lansia sebesar 3,47. Kedua nilai tersebut termasuk rentang nyeri sedang.

\section{Analisa Bivariat}

Hasil uji bivariat disajikan dalam tabel berikut

\begin{tabular}{|c|c|c|}
\hline & Jumlah & Nilai $p$ \\
\hline Menurun & 23 & 0,000 \\
\hline Meningkat & 2 & \\
\hline Sama & 13 & \\
\hline
\end{tabular}

Sumber: Data Primer 2018

Berdasarkan tabel tersebut diketahui bahwa terdapat perbedaan yang signifikan antara nyeri kepala sebelum dan setelah teknik relaksasi autogenik dengan nilai $\mathrm{p}$ : 0,000 .

\section{Karakteristik Responden}

Hipertensi adalah tekanan darah yang konstan dengan tekanan sistoliknya di atas $140 \mathrm{mmHg}$ dan tekanan diastolik di atas 90 $\mathrm{mmHg}$. Hipertensi pada populasi lansia didefinisikan sebagai tekanan darah dengan sistolik lebih dari $160 \mathrm{mmhg}$ dan tekanan diastolik lebih dari $90 \mathrm{mmHg}$. Rekomendasi JNC 8 Committee tekanan darah harus dikontrol di bawah 140/90 mmHg. ${ }^{11}$

Hasil penelitian menunjukkan bahwa rata-rata tekanan darah responden yaitu $165,13 / 91,32 \mathrm{mmHg}$ dan termasuk kategori hipertensi derajat 2. Hasil penelitian ini sejalan dengan penelitian tentang pengaruh relaksasi autogenik terhadap tekanan darah pada lansia di Kelurahan Mersi, Purwokerto yaitu rata-rata tekanan darah lansia lansia sebesar 163,94/91,39 mmHg dan termasuk kategori hipertensi derajat $2 .^{10}$

Seiring bertambahnya usia, maka kemungkinan terjadi hipertensi menjadi semakin besar. Penyakit hipertensi merupakan penyakit yang timbul akibat adanya interaksi dari berbagai faktor risiko terhadap timbulnya hipertensi. ${ }^{12}$ Lansia sering mengalami isolated systolic hypertension (ISH) yaitu kondisi di mana hanya tekanan sistolik saja yang meningkat. Kemungkinan ISH disebabkan karena aterosklerosis di arteri besar sehingga mengakibatkan penurunan elastisitas arteri tersebut. Walaupun demikian, ISH dipercayai sebagai bagian normal dari proses 
penuaan. ${ }^{3}$ Beberapa faktor risiko hipertensi pada lansia adalah 1) perubahan struktur pembuluh darah; 2) kekakuan pembuluh darah dan menurunnya daya lentur (elastisitas) dari pembuluh darah; dan 3) penurunan fungsi ginjal yang alamiah. ${ }^{12}$

Komplikasi penyakit hipertensi pada kardio seperti krisis hipertensi, angina pektoris, infark miokardium, dan aritmia. Peningkatan denyut jantung disebabkan aktivitas sistem syaraf simpatis, dan sebaliknya, penurunan denyut jantung disebabkan oleh aktivitas syaraf parasimpatis. Pusat kontrol serebral jantung dilakukan oleh hipotalamus. Hasil penelitian ini menunjukkan rata-rata denyut jantung lansia sebesar 89,00x/menit termasuk rentang normal. Denyut jantung utamanya dipengaruhi oleh aktivitas pacemaker pada nodus sinoatrial (SA). Penurunan denyut jantung dapat terjadi karena blok atau kegagalan pada nodus SA, sedangkan peningkatan denyut jantung dapat terjadi karena fokus ektopik. Peningkatan denyut jantung juga dapat disebabkan karena respon stres, nyeri, peningkatan aktivitas, kurang tidur, kelebihan kafein, nikotin, atau konsumsi alkohol. ${ }^{4}$

Pengukuran tekanan darah dan denyut jantung responden penelitian ini dilakukan dalam posisi duduk minimal 20 menit setelah berjalan atau berdiri. Fase istirahat selama itu menyebabkan penurunan stres sehingga terjadi peralihan aktivitas syaraf simpatis menjadi aktivitas syaraf parasimpatis. Hal tersebut dapat menyebabkan denyut jantung responden dalam rentang normal.

\section{Nyeri sebelum teknik relaksasi autogenik}

Perasaan nyeri seseorang merupakan manifestasi dari suatu akumulasi berbagai rangsangan stimulus. Stimulus dapat berasal dari luar tubuh maupun akibat ketidakseimbangan kondisi keseluruhan tubuh manusia. ${ }^{13}$ Manusia senantiasa menjalankan homeostasis. Rasa nyeri merupakan suatu tanda peringatan bagi tubuh untuk menghentikan aktivitas dalam rangka menjaga keseimbangan terhadap lingkungan sekitarnya, agar tidak terjadi kerusakan jaringan yang lebih parah di suatu organ. ${ }^{14}$ Kondisi hipertensi mengakibatkan nyeri kepala karena peningkatan tekanan intra kranial, bertambah setiap pagi dan sering dilaporkan bersamaan dengan mual muntah. Hipertensi juga menyebabkan pusing (dizziness, confusion) karena penurunan perfusi jaringan. Vasokonstriksi pembuluh darah menyebabkan iskemia. ${ }^{3}$

Hasil penelitian ini menunjukkan bahwa rata-rata nyeri kepala sebelum teknik relaksasi autogenik pada lansia sebesar 5,24 . Nilai tersebut termasuk dalam rentang nyeri sedang. Nyeri kepala merupakan keluhan paling umum pada pasien. Sejumlah $90 \%$ nyeri kepala disebabkan karena kelainan vaskular, kontraksi otot, atau kombinasi keduanya. Penyakit hipertensi menyebabkan konstriksi arteri intrakranial 
dan ekstrakranial. Selama serangan nyeri kepala, akan terjadi abnormalitan biokimia seperti penurunan polipeptida vasokonstriktor yaitu neurokinin. Fungsi neurokinin untuk mendilatasi arteria dan menurunkan kadar serotonin dalam plasma. ${ }^{3}$

Terdapat empat fase terjadinya nyeri kepala yaitu pertama fase normal. Belum terjadi perubahan atau kerusakan arteri serebral dan temporal. Kedua yaitu fase vasokonstriksi (aura). Terjadi vasokonstriksi neurogenik lokal yang terinduksi karena stres di arteri serebral. Hal ini akan menurunkan aliran darah ke otak menyebabkan iskemia lokal. Prostaglandin dan tromboksan meningkat dan menyebabkan agregasi platelet di sel dinding pembuluh darah. Pelepasan serotonin yang menyebabkan vasokonstriksi pembuluh darah lebih meluas. Ketiga yaitu fase dilatasi arteri parenkimal. Keadaan asidosis dan anoksia atau iskemia lokal di jaringan serebral menyebabkan vasodilatasi arteri parenkim. Kondisi ini dipengaruhi juga oleh faktor biologis dan neurogenik lainnya seperti peningkatan aliran darah, peningkatan tekanan intrakranial yang akan menyebabkan nyeri kepala. Fase keempat yaitu vasodilatasi (nyeri kepala). Mekanisme kompensasi karena vasodilatasi pembuluh darah parenkimal menyebabkan nyeri. ${ }^{15}$

\section{Perbedaan nyeri sebelum dan setelah teknik relaksasi autogenik}

Penatalaksanaan nyeri meliputi pendekatan farmakologi dan non farmakologi. Pendekatan farmakologi yang sering digunakan yaitu analgetik golongan opioid untuk nyeri yang hebat dan golongan non steroid untuk nyeri sedang atau ringan. ${ }^{6}$ Perawat mulai banyak menggunakan metode non farmakologi seperti terapi komplementer untuk menurunkan nyeri. ${ }^{16}$ Hasil penelitian menunjukkan terdapat 23 responden (61\%) mengalami penurunan nyeri kepala. Nilai rata-rata nyeri kepala sebelum teknik relaksasi autogenik pada lansia sebesar 5,24, dan rata-rata nyeri kepala setelah teknik relaksasi autogenik pada lansia sebesar 3,47 termasuk rentang nyeri sedang. Perbedaan nyeri kepala sebelum dan setelah relaksasi autogenik secara statistik signifikan dengan nilai $p$ : 0,000 .

Penelitian ini sejalan dengan penelitian tentang pengaruh pemberian formula PHISIK (Pijat, Hipnotis dan Musik) terhadap intensitas nyeri pasca bedah jantung di RS PJN Harapan Kita Jakarta yang menunjukkan hasil terjadi penurunan nyeri yang signifikan dengan nilai p: 0,000. Skala nyeri setelah pemberian terapi musik menurun sebesar 1,05 poin. Skala nyeri setelah pemberian kombinasi terapi musik dan hipnosis menurun sebesar 2,44 poin, 
dan skala nyeri setelah pemberian kombinasi terapi PHISIK menurun sebesar 3,67 poin. ${ }^{17}$

Relaksasi dari perspektif neuro fisiologi diyakini mempunyai efek hipnoanalgesia karena penghambatan pada berbagai level di sistem syaraf. Level yang dipengaruhi yaitu Central Nervous System (CNS). Neuron yang tereksitasi akan mengeluarkan signal/firing sehingga otak mempersepsikan adanya nyeri. Agar mencegah terjadinya sensory overload maka neuron yang tereksitasi harus dihambat aktivitasnya agar tidak melepaskan sinyal tersebut. Berbagai penelitian menunjukkan aktivitas otak berubah ketika relaksasi berlangsung. ${ }^{18}$ Aktivitas listrik otak di regio frontal sinistra korteks serebral akan meningkat sehingga respon nyeri berkurang. ${ }^{19}$ Efek relaksasi juga akan menurunkan tingkat kesadaran dan mengaktifkan mekanisme anti nosiseptif pada syaraf spinal, mengaktifkan diffuse noxious inhibitory control (DNICs) sehingga menyebabkan pergeseran persepsi nyeri ke relaksasi. ${ }^{18}$

Individu membutuhkan stimulus sensasi sakit yang lebih tinggi untuk memberikan efek respon pada sistem syaraf. Hipnoanalgesia mampu menghambat pola di otak. Setelah induksi relaksasi berupa tidak mesensasikan stimulus sensasi sakit menyebabkan seseorang lebih tidak awas terhadap sensasi sakit. Hipnoanalgesia seperti relaksasi autogenik berkaitan erat dengan gelombang theta di otak. Pola gelombang theta merupakan pola mereduksi penyampaian sinyal (inhibitory), yang diasosiasikan dengan pikiran bawah sadar. Sugesti hipoanalgesia seperti relaksasi autogenik langsung menuju ke bagian tengah bawah untuk mengendalikan dan mereduksi nyeri. ${ }^{20}$

Efek relaksasi autogenik juga membuat tubuh menjadi rileks dengan mengendalikan pernafasan, tekanan darah, denyut jantung, dan suhu tubuh. ${ }^{21}$ Sensasi hangat tercipta karena vasodilatasi arteri perifer. Respon emosi pasien menjadi lebih nyaman dan tenang. Respon simpatis akan diambil alih oleh respon parasismpatis. ${ }^{9}$ Pengaruh syaraf parasimpatis pada sistem sirkulasi akan menurunkan atau menormalkan denyut jantung, tahanan perifer, dan tekanan darah sehingga terjadi penurunan tekanan intrakranial dan nyeri kepala. ${ }^{22}$

Terdapat 13 responden (34\%) yang meningkat nyerinya setelah pemberian teknik relaksasi autogenik. Hal ini dapat disebabkan selama sugesti sensasi hangat di tangan dan kaki tidak tercapai sempurna. Latihan sensasi hangat pada beberapa pasien terkadang tercapai setelah 2-3 kali latihan. Sensasi hangat merupakan indikasi pembuluh darah telah berdilatasi dan rileks sehingga nyeri yang dirasakan pasien akan berkurang. Upaya yang dapat dilakukan apabila pasien mengalami kesulitan untuk mensugesti rasa hangat dengan memberikan handuk hangat sebagai alas 
tangan dan kaki, atau menggosokkan kedua telapak tangan. ${ }^{23}$

Terdapat 2 responden (5,26\%) yang meningkat nyerinya setelah pemberian teknik relaksasi autogenik. Hal tersebut kemungkinan dapat disebabkan karena pasien mengalami nyeri kronik. Hipertensi yang menahun akan menyebabkan nyeri kronik yang berlangsung selama 3 bulan atau lebih, bersifat dalam, tumpul, diikuti dengan berbagai macam gangguan seperti gangguan penglihatan yang sering dikeluhkan pasien hipertensi. Proses terjadi nyeri kronik berlangsung lambat dan meningkat secara perlahan dimulai setelah detik pertama dan meningkat perlahan sampai beberapa detik atau menit. Nyeri ini biasanya berhubungan dengan kerusakan jaringan yang sifatnya terus-menerus. Nyeri kronis sering sulit untuk diobati karena nyeri ini tidak mempunyai pengobatan yang diarahkan pada penyebabnya. ${ }^{2}$ Faktor lain yang mempengaruhi seperti usia responden yaitu lansia. Keluhan nyeri pada lansia merupakan sesuatu yang biasa terjadi sehingga lansia berusaha menutupi keluhan nyeri yang mengganggu dan mengabaikan upaya untuk menurunkan nyeri tersebut. ${ }^{3}$

Keyakinan dan sugesti terhadap tindakan merupakan harapan positif yang dimiliki oleh pasien terhadap tindakan pengobatan dapat meningkatkan keefektifan medikasi atau intervensi yang lainnya. ${ }^{24}$ Latihan relaksasi autogenik membutuhkan waktu sekitar 3-4 menit pada setiap fase, total berlangsung selama 15-20 menit. $^{25}$ Setiap pasien dapat berbeda kemampuan diri untuk menerima sugesti relaksasi autogenik dan kecepatan mencapai tahapan kedalaman sugesti. ${ }^{26}$

\section{KESIMPULAN}

Kesimpulan hasil penelitian ini yaitu nilai rata-rata nyeri kepala sebelum teknik relaksasi autogenik pada lansia sebesar 5,24 , dan rata-rata nyeri kepala setelah teknik relaksasi autogenik pada lansia sebesar 3,47 termasuk rentang nyeri sedang. Serta terdapat perbedaan yang signifikan antara nyeri kepala sebelum dan setelah teknik relaksasi autogenik dengan nilai p: 0,000 .

Saran bagi lansia dengan hipertensi dapat melakukan relaksasi autogenik secara rutin agar dapat menurunkan nyeri kepala. Serta bagi peneliti lain, sebagai bahan rencana penelitian selanjutnya dengan menambahkan variabel yang belum diteliti dan belum dikontrol dalam penelitian ini serta mengombinasikan dengan terapi komplementer lainnya

\section{TERIMA KASIH}

1. Dr Pramesti Dewi, M.Kes, ketua STIKES Harapan Bangsa Purwokerto, Jl. R Patah No 100, Ledug, Kembaran, Purwokerto, email pramesti.shb@gmail.com

2. Ema Wahyuningrum. S.SiT., M.Kes, 
ketua Lembaga Penelitian dan

Pengabdian Kepada Masyarakat STIKES

Harapan Bangsa Purwokerto, Jl. R Patah

No 100, Ledug, Kembaran, Purwokerto,

Email em4wahyuningrum@gmail.com

\section{KEPUSTAKAAN}

1. Karavidas, A., Lazaros, G., Tsiachris, D., Pyrgakis, V.Aging and the Cardiovascular System. Hellenic $J$ Cardiol. 3 Maret 2010; Volume 51, Hal. 421-427.

2. Potter. P. A., Perry, A. G. Fundamentals of nursing: concept, process, and practice. $7^{\text {th }}$ ed. Jakarta: Salemba Medika; 2009.

3. Munson, C., Traister, R. Pathophysiology: a 2-in-1 reference for nurses. Philadelphia: Lippincott Williams \& Wilkins; 2015.

4. Tortora, J., Derrickson, B. Introduction to the human body: the essentials of anatomy and physiology. 8 th ed. New York: John Wiley \& Sons, Inc.; 2010.

5. Sherwood, L. Fundamentals of Human Physiology. Fourth Edition. Belmont: Brooks/Cole, Cengage Learning; 2012.

6. Durkin, M.T., Hodgson, B.E . Nursing Pharmacology Made Incredibly Easy: Incredibly Easy Series. Lippincott: Williams \& Wilkins; 2013.

7. Bulechek, G,M., Butcher, H,K., Dochterman, J, M., Wagner, C,M. Nursing Interventions Classification (NIC). $6^{\text {th }}$ ed. Missouri: Elsevier; 2013.

8. Micah, R.S. Autogenic Training: A MindBody Approach to the Treatment of Chronic Pain Syndrome and StressRelated Disorders. McFarland; 2012.

9. Oberg, E. B. Mind-body techniques to reduce hypertension's chronic effects. Integr Med Clin J. 8 Mei 2009: Volume 8 (5), Hal 52-57.

10. Novitasari, D. Pengaruh Relaksasi Autogenik terhadap Penurunan Tekanan darah pada Lansia dengan Hipertensi di Kelurahan Mersi Purwokerto. Prosiding 2016 Seminar hasil-hasil penelitian dan pengabdian kepada masyarakat pelayanan kesehatan integratif berdasarkan evidence based sebagai upaya peningkatan kesehatan komunitas dalam mencapai SDG's. LPPM Stikes Harapan Bangsa Purwokerto. 17 Novermber 2017, Hal 126-132.

11. Black, H.R., Sica, D.C., Ferdinand, K., White, W.B. Eligibility and Disqualification Recommendations for Competitive Athletes With Cardiovascular Abnormalities: Task Force 6: Hypertension. Circulation. 1December 2015: Volume 132, Hal e298-e302

12. Sutanto. Cekal Penyakit Modern Hipertensi, Stroke, Jantung, Kolesterol, dan Diabetes. Yogyakarta: Andi Offset: 2010.

13. Caudill, M.A. Managing pain before it manages you. $4^{\text {th }}$ ed. New York: Guilford Publications; 2016.

14. Budi, P.P., Rizali, E. Hypnohealing. Yogyakarta: Leutika

15. Sharon, R.E. Ann-Essential Pathophysiology For Nursing And Healthcare Student. USA: McGraw-Hill Education: 2014

16. McCuistion, L.E., Kee. J.L., Hayes, E.R. Study Guide For Pharmacology: A Patient-Centered Nursing ProcessApproach. Philadelphia: WB Saunders; 2014.

17. Awaludin, S., Nurrachmah, E., Herawati, T. Pengaruh Formula PHISIK (Pijat, Hipnosis, dan Musik) untuk Menurunkan Skala Nyeri Pasca Bedah Jantung. Tidak dipublikasikan. Universitas Indonesia: 2013.

18. Sandrini, G., et al. Effects of hypnosis on diffuse noxious inhibitory controls. Physiology \& behavior. 13 Desember 2000: Volume 69 (3), Hal: 295-300.

19. Kirsch,I. Hypnosis: Theory, research and application. New York: Taylor \& Francis; 2017.

20. Dickenson, A.H. Pain, brain and opium. Behavioral and Brain Science. 1 September 1997. Volume 20 (3), Hal: 479-482 
21. Varvogli, L., Darviri, C. Stress management techniques: evidencebased procedures that reduce stress and promote health. Health Science Journal. 2011. Volume 5 (2), Hal: 74.

22. Martha, D., Eshelman, E.R., McKay, $\mathrm{M}$. The relaxation and stress reduction workbook. New York: New Harbinger Publications; 2008.

23. Sonia, S.,Chairman, B.A.S. Autogenic therapy: Short term therapy for long term gain. British autogenic Society: http://www. autogenic therapy. org. Uk; 2007.
24. Sylvain, N., Stephenson, R. Effectiveness of hypnotherapy with cancer patients' trajectory: emesis, acute pain, and analgesia and anxiolysis in procedures. Intl. Journal of Clinical and Experimental Hypnosis. 2007. Volume 55 (3), Hal: 336-354.

25. Widyastuti, P. National Safety Council. Stress Management. Jakarta: EGC: 2004

26. Gafner, G., Benson, S. Hypnotic techniques: for standard psychotherapy and formal hypnosis. New York: Norton; 2013 